\title{
ANÁLISE MICROBIOLÓGICA DE OSSOS DE CÃES CONSERVADOS POR LONGO PERÍODO DE TEMPO NA GLICERINA A 98\% À TEMPERATURA AMBIENTE, OBJETIVANDO A ENXERTIA ÓSSEA ${ }^{1}$
}

\author{
Marco Antonio Gioso ${ }^{2}$ \\ Nilson Roberti Benites ${ }^{3}$ \\ Gabriela Kämpf ${ }^{4}$
}

\begin{abstract}
Gioso MA, Benites NR, Kampf G. Análise microbiológica de ossos de cães conservados por longo período de tempo na glicerina a $98 \%$ à temperatura ambiente, objetivando a enxertia óssea. Acta Cir Bras [serial online] 2002 Jul-Ago;17(4). Disponível em URL: http://www.scielo.br/acb.
\end{abstract}

RESUMO - Objetivo: Verificar crescimento de microorganismos em amostras de glicerina e ossos armazenados durante nove anos. Métodos: Realizou-se a análise microbiológica da epífise e da medula de ossos conservados na glicerina a $98 \%$, bem como da própria glicerina que os contêm. Resultado: $\mathrm{O}$ crescimento microbiano observado não foi estatisticamente significante. Conclusão: A glicerina é um excelente meio para conservação de tecido ósseo por longo período de tempo.

DESCRITORES - Microorganismos. Glicerol. Ossos. Cão. Fratura. Medula. Epífise.

\section{INTRODUÇÃO}

A enxertia óssea de ossos homólogos na ortopedia veterinária é um meio seguro e de eleição na reposição de perdas e falhas ósseas em fraturas ou ressecções amplas. Para o procedimento cirúrgico de enxertia é necessário que os ossos para implante sejam previamente retirados do animal doador, sob rigorosa assepsia e preservados num meio adequado. Sabe-se que a glicerina é reconhecidamente um meio viável para esta finalidade, obtendo-se bons resultados na conservação de ossos e tecidos. Este trabalho visou pesquisar o crescimento de microorganismos no tecido ósseo e/ou na glicerina que o contém, armazenada durante um longo período de tempo, e identificá-los caso houvesse crescimento nos meios de cultura. Este estudo é fundamental para comprovar a viabilidade da implantação de bancos de ossos em hospitais veterinários, tendo em vista a enxertia óssea.

Fraturas de ossos em membros locomotores são frequientes em pequenos animais. Fraturas cominutivas ou multifragmentares são os traumatismos que apresentam maior dificuldade de tratamento. Em geral, a osteossíntese nesses casos não apresenta boa evolução pós-operatória. No entanto, a enxertia óssea na ortopedia veterinária tem sido uma alternativa segura e de eleição na reposição de perdas e falhas ósseas ${ }^{1}$. Para isso torna-se necessário que os implantes homólogos sejam previamente retirados do animal doador e preservados em meio adequado ${ }^{2}$.

Porém, há uma série de fatores limitantes na obtenção dos implantes ósseos: devido à grande variação dos tamanhos dos esqueletos dos animais, as possibilidades de se encontrar um doador que seja compatível com a conformação física do animal receptor diminui consideravelmente ${ }^{2,3}$; também é difícil obter ossos de cães doadores imediatamente para a cirurgia de enxertia, pois é necessária a remoção total de periósteo e restos teciduais aderidos ao osso para que não haja rejeição ao implante ${ }^{4}$, procedimento que atrasaria consideravelmente o início da cirurgia. Além disso, é preciso que o método de preservação seja viável, de fácil utilização, baixo custo e que seja acessível a clínicas e ambulatórios cirúrgicos de pequenos animais ${ }^{4}$.

As intervenções cirúrgicas oncológicas, devido às suas ressecções amplas, frequientemente tornam necessário o uso de osso para transplantação. O transplante autólogo poderia ser substituído por osso conservado, o que condiciona o cirurgião a previamente armazenar o osso preservado e transplantável, sendo a glicerina pura um bom método de manutenção deste tecido. Porém, não se sabia ainda se era possível manter durante 
longo período de tempo os ossos conservados na glicerina, e além disso não se sabiam quais microorganismos eventualmente poderiam desenvolver-se nas amostras armazenadas por longos períodos de tempo ${ }^{2,3}$.

Diversas técnicas têm sido desenvolvidas no intuito de se tornar possível a conservação dos tecidos ósseos por longos períodos de tempo. Dentre estas, a conservação em glicerina tem merecido destaque pois, além de ser um método acessível economicamente, não é necessário empregar a autoclavagem e tampouco o congelamento, técnicas que causam danos ao tecido ósseo, e prejudicam a formação de calo ósseo no pós-cirúrgico; além disso, não foi observada diferença considerável quanto ao crescimento de microorganismos na glicerina a $98 \%$ autoclavada e "in natura", num período igual ou menor a 24 meses $^{4}$, tampouco rejeição do organismo ao meio conservante na evolução pós-operatória.

\section{OBJETIVO}

Verificar o crescimento bacteriano e fúngico das epífises e da medula de ossos conservados na glicerina a $98 \%$, bem como da própria glicerina que os contêm. Fazer a identificação dos microorganismos eventualmente encontrados em cada amostra. Analisar a viabilidade da implantação de um banco de ossos de cães conservados na glicerina à temperatura ambiente.

\section{MÉTODOS}

\section{Amostra}

Metacarpos (MC) e metatarsos (MT) de cães clinicamente sadios, removidos cirurgicamente de modo totalmente asséptico, estocados em frascos estéreis e preenchidos com solução de glicerina a 98\%, conservados à temperatura ambiente e em ambiente fresco e seco, durante o período de nove anos. Os tubos de ensaio contendo os ossos estavam armazenados em recipiente cirúrgico de alumínio, e dispostos em 24 tubos contendo um osso cada, preenchidos com glicerina de modo que o osso esteja totalmente coberto, tampados com algodão; três tubos totalmente preenchidos com glicerina, sem nenhuma amostra de osso (pois foram utilizados em casos cirúrgicos), tampados com algodão; e três tubos contendo pequena quantidade de glicerina, não tampados com algodão (os ossos foram utilizados em casos cirúrgicos).

Há que se ressaltar que o algodão utilizado não era hidrofóbico, o que permitiu que parte da glicerina fosse absorvida por ele; isto permitiu maior contato com o meio externo e possibilitou, em tese, a contaminação das amostras.
Para referir-se a cada um dos grupos, foram utilizadas as seguintes siglas: Tgo (tubos fechados contendo fragmentos ósseos preservados na glicerina); $\mathbf{T g}$ (tubos fechados preenchidos com glicerina que não contêm os fragmentos ósseos); Tgc (tubos preenchidos parcialmente pela glicerina e sujeitos à contaminação (abertos).

\section{Análise Microbiológica}

Três meios de cultura foram eleitos para se cultivar microorganismos: Agar-Sangue, Sabouraud e BHI. As placas de Ágar-Sangue foram divididas em dois grupos: o primeiro, cultivado em meio aeróbico, e o segundo, cultivado em meio anaeróbico. As placas de ambos os procedimentos foram semeadas de forma semelhante.

Todas as placas que sofreram os procedimentos aeróbico e anaeróbico permaneceram na estufa a $37^{\circ}$ C. As placas que sofreram procedimento anaeróbico foram dispostas em jarra de anaerobiose, com sachê gerador anaerobiose, cujo conteúdo reage com o oxigênio do meio produzindo água e tornando conseqüentemente a atmosfera anaeróbica. Somente as placas de Sabouraud permaneceram à temperatura ambiente, não foram à estufa. A leitura das placas e de seus respectivos meios de enriquecimento foi feita a cada 24 horas, por até cinco leituras consecutivas. A cada leitura, a jarra foi aberta e o gerador de anaerobiose substituído.

\section{RESULTADOS}

\section{Ossos - Medula e Epífise}

Ágar-Sangue em aerobiose: Medula: detectouse crescimento de colônias bacterianas em duas das 24 placas: tgo2 e tgo11. As duas amostras foram ressemeadas. Não houve crescimento de bactérias após a ressemeadura em ambas as amostras. A amostra tgo11 foi ressemeada mais uma vez, e novamente microorganismos não foram identificados. Epífise: houve crescimento bacteriano em uma das 24 placas; uma colônia de Staphylococcus na placa tgo3 foi identificada por Gram. Ágar Sangue em anaerobiose: Não foi verificado crescimento microbiano em medula, epífise e glicerina. BHI: Não foi verificada a turvação do meio em amostras de medula, epífise e glicerina. Sabouraud: Não foi verificado crescimento de colônias de fungos em medula, epífise e glicerina.

\section{Glicerina}

Ágar-Sangue em aerobiose: Foi observado crescimento de nove colônias puntiformes, brilhantes 
e amarelas em placa Tgc 29; como de costume, realizouse o procedimento de Gram, constatando-se a presença de bacilos gram positivos. Cabe dizer que este tubo encontrava-se aberto, sem fragmento ósseo, com glicerina em pouca quantidade e portanto sujeito à contaminação. Ágar-Sangue em anaerobiose: Não foi verificado crescimento microbiano em medula, epífise e glicerina. BHI: Não foi verificada a turvação do meio em amostras de medula, epífise e glicerina. Sabouraud: Não foi verificado crescimento de colônias de fungos em medula, epífise e glicerina.

\section{Cálculos}

Calculou-se a porcentagem de placas que continham microorganismos sobre o número total de placas, conforme mostra a Tabela 1.

Tabela 1 - Porcentagens de isolamento de microorganismos das 30 amostras de glicerina, dentre elas 24 que continham fragmentos ósseos (Tgo) e seis que continham somente glicerina (Tg e Tgc).

\begin{tabular}{lllc}
\hline \multicolumn{1}{c}{ n } & & n' & \% \\
\hline Glicerina & 30 & 1 & $0,00333 \%$ \\
\hline Medula & 24 & 2 & $0,08333 \%$ \\
\hline Epífise & 24 & 1 & $0,04166 \%$ \\
\hline
\end{tabular}

Onde

$\mathrm{n}=$ número considerado de amostras

n'= número de amostras onde houve isolamento microbiano

$\%=$ porcentagem $(\mathrm{n} / \mathrm{n})$

Estes resultados demonstram que não há diferença estatisticamente significativa para $\mathrm{P}<0,05$.

Para a quantidade total de amostras $(n=24)$ foi calculado o índice de concordância Kappas:

Tabela 2 - Concordância de resultados entre as amostras de epífise e glicerina, analisada pelo índice de concordância Kappa.

\begin{tabular}{l|c|c|c}
\hline \multicolumn{1}{c|}{ Epífise } & Glicerina & Positivo & Negativo \\
\hline Positivo & $\mathbf{0}$ & $\mathbf{0}$ & $\mathbf{0}$ \\
\hline Negativo & $\mathbf{1}$ & $\mathbf{2 3}$ & $\mathbf{2 4}$ \\
\hline & $\mathbf{1}$ & $\mathbf{2 3}$ & $\mathbf{2 4}$ \\
\hline
\end{tabular}

Índice Kappa: 0,9583

Concordância: ótima
Tabela 3 - Concordância de resultados entre as amostras de medula e glicerina, analisada pelo índice de concordância Kappa.

\begin{tabular}{l|c|c|c}
\hline \multicolumn{1}{c|}{ Medula } & Glicerina & Positivo & Negativo \\
\hline Positivo & $\mathbf{0}$ & $\mathbf{0}$ & $\mathbf{0}$ \\
\hline Negativo & $\mathbf{2}$ & $\mathbf{2 2}$ & $\mathbf{2 4}$ \\
\hline & $\mathbf{2}$ & $\mathbf{2 2}$ & $\mathbf{2 4}$ \\
\hline
\end{tabular}

Índice Kappa: 0,9167

Concordância: ótima

Tabela 4 - Concordância de resultados entre as amostras de medula e epífise, analisada pelo índice de concordância Kappa.

\begin{tabular}{l|c|c|c}
\hline \multicolumn{1}{c|}{ Epífise } & Medula & Positivo & Negativo \\
\hline Positivo & $\mathbf{0}$ & $\mathbf{1}$ & $\mathbf{1}$ \\
\hline Negativo & $\mathbf{2}$ & $\mathbf{2 1}$ & $\mathbf{2 3}$ \\
\hline & $\mathbf{2}$ & $\mathbf{2 2}$ & $\mathbf{2 4}$ \\
\hline
\end{tabular}

Índice Kappa: 0,9167

\section{Concordância: ótima}

É preciso salientar que o cálculo de concordância através do índice Kappa foi calculado baseando-se no número de amostras de glicerina que continham osso $(n=24)$. As amostras sem osso $(n=6)$ foram semeadas com a finalidade de comparação com as amostras que continham ossos, e portanto não foram consideradas no cálculo.

\section{DISCUSSÃO}

Os índices de concordância Kappa mostram-nos que a concordância é ótima para todos os grupos de comparação. Este é um excelente resultado, visto que somente com a semeadura da glicerina já é possível avaliar-se a viabilidade do tecido ósseo. Isto significa que se o osso não estiver contaminado quando de sua estocagem, pode-se utilizar somente a cultura da glicerina para se avaliar a presença de microorganismos em medula e epífise, poupando-nos do trabalhoso procedimento de coleta de material de epífise e serragem do osso para coleta de medula óssea. Sobretudo, a simples manipulação dos ossos, por mais cuidadosa que seja, sempre introduz microorganismos contaminantes nas amostras. Questionou-se quais microorganismos desenvolver-se-iam eventualmente nas amostras conservadas por longo período de tempo ${ }^{6}$; pelo presente trabalho soube-se que o crescimento de microorganismos nas amostras conservadas há nove anos não é estatisticamente significante. 
Em 1951, foram realizados experimentos com um banco de ossos preservados em solução aquosa de Timerosal, afirmando ser este um método de preservação simples, barato e asséptico ${ }^{1}$; cremos, todavia, que a glicerina também é um meio de preservação simples, barato e asséptico, tal como o Timerosal o era, e o substitui com sucesso. É possível armazenar o banco de ossos imersos em glicerina à temperatura ambiente, não sendo necessário o congelamento e outros métodos lesivos ${ }^{7,8,9}$; esta é outra vantagem da utilização da glicerina, pois armazenando-se à temperatura ambiente não há formação de cristais intra e extracelulares, além de alterações eletrolíticas deletérias às células e potencialmente destrutivas à matriz óssea. Seu efeito asséptico na conservação de tecido ósseo deve-se particularmente às suas propriedades físicas ${ }^{10}$, e portanto não há problema quanto ao fenômeno da resistência bacteriana, assim como ocorre atualmente com o Timerosal.

A esterilização permanece como o maior problema na enxertia, sendo freqüiente a contaminação bacteriana, fúngica e viral ${ }^{3}$; devido a este fato diversos autores estudaram a viabilidade do óxido de etileno como meio de conservação de fragmentos ósseos 4,11,12,13,14,15. Porém, sua viabilidade é questionável após 32 semanas de estocagem ${ }^{13}$, sendo que o período máximo de estocagem aceitável é de seis a 18 meses $^{2,3}$. Pelo presente trabalho pôde-se constatar que a glicerina é capaz de conservar o tecido ósseo por um prazo de nove anos de armazenamento (108 meses aproximadamente), superando o óxido de etileno neste aspecto. Levando-se em consideração que o número de amostras positivas para crescimento microbiano é estatisticamente muito pequeno em comparação com as amostras negativas, deve-se considerar, portanto, a glicerina como um excelente meio de conservação de tecido ósseo, mantendo o tecido isento de microorganismos por um período de até nove anos.

Em 1991 foi verificada a desidratação do implante conservado no óxido de etileno, levando à perda de suas propriedades mecânicas ${ }^{12}$; no presente trabalho, verificou-se que glicerina estocada por nove anos impediu o ressecamento da medula contida no osso, o que nos leva a crer que a glicerina realmente possui propriedade protetora das células como também atua como um meio impermeável à evaporação da água, desde que não esteja em contato direto com o tecido medular.

A utilização de fragmentos esterilizados por raios ionizantes é muito onerosa ${ }^{16}$; cremos desta forma que a glicerina é muito acessível economicamente, e pode ser utilizada facilmente por hospitais e clínicas veterinárias com a finalidade de se montar um banco de ossos.
Excelentes resultados na reparação de fraturas com fragmentos ósseos conservados na glicerina a $98 \%$ foram obtidos ${ }^{2}$. Nosso trabalho confirmou a viabilidade da utilização da glicerina por longo período de tempo, fato que vem acrescentar mais uma vantagem à utilização da glicerina em detrimento das outras técnicas de conservação de ossos.

Cabe comentar que os ossos continham suas medulas ósseas ainda íntegras, após nove anos de armazenamento na glicerina, e que estas preenchiam todo o canal medular do osso. A coloração era róseapálida e não houve ressecamento, sendo possível aspirar seu conteúdo por vácuo com seringa descartável.

Um achado curioso ocorreu nas placas de ÁgarSangue semeadas com conteúdo de medula óssea: a descoloração circunscrita à área semeada, causada por lise de hemácias do meio de cultura de Agar-Sangue por substância constituinte da medula óssea.

Tomando-se por base os dados finais, após nove anos de estocagem de ossos em glicerina, pode-se observar que não houve diferença significante $(\mathrm{P}<0,05)$ para isolamento de microorganismos. Portanto, consideram-se as amostras como sendo estéreis, e a glicerina um excelente meio de armazenamento de tecido ósseo.

\section{CONCLUSÃO}

Pelo presente trabalho pudemos comprovar que a glicerina é um excelente meio de conservação de tecido ósseo, viabilizando a implantação de um banco de ossos de cães pelo período de até nove anos de armazenamento.

\section{AGRADECIMENTOS}

Priscilla Anne Melville, Médica Veterinária responsável pelo Laboratório de Doenças Infecciosas, Bacteriologia e Micologia da Faculdade de Medicina Veterinária e Zootecnia da USP.

À FAPESP, pelo auxílio financeiro e bolsa concedida.

\section{REFERÊNCIAS}

1. Reynolds FC, Oliver DR, Ramsey R. Clinical evaluation of the merthiolate bone bank and homogenous bone graft. J Bone Jt Surg 1951; 33: 873-7.

2. Pinto Jr HS. Utilização de enxertos ósseos homólogos preservados na reparação de fraturas cominutivas de ossos longos de cães[Tese - Mestrado]. FMVZ-USP; 1990.

3. Pinto Jr HS. Utilização de enxerto ósseo cortical homólogo preservado em tintura de iodo a $2 \%$ na reparação de fraturas cominutivas de ossos longos de cães [Tese - Doutorado]. FMVZUSP; 1995.

4. Roe SC, Pijanowsky GJ, Johnson AL. Biomechanical properties of canine cortical bone allografts: effects of preparation and storage. Am J Vet Res 1988; 49(6): 873-7. 
5. Landis JR, Koch GG. The measurement of observer agreement for categorical date. Biometrics 1977;33:159-74.

6. Marques A, Leite JBF, Marziona F, Giannotti Fo O, Moreira FA, Abrão FS, Gentil FC, Magrin J, Erlich DH. Osso homólogo conservado em glicerina: estudo experimental em cobaios. Rev Paul Med 1980; 95:14-9.

7. Bloomberg MS, Cring RL, Born F. Frozen diaphiseal bone allografts combined with external pin splintage in small animal orthopedic surgery. J Am Anim Hosp Assoc 1984; 20: 393-402.

8. Hart MM, Campbel ED, Kartub MG. Bone banking: a cost effective method for establishing community hospital bone bank. Clin Orthop Res 1984; 206: 295-300.

9. Schena CJ, McCurning DM. The use of fresh cortical and cancelous allografts in the repair of fractured femur in a dog: a case report. J Am Anim Hosp Assoc 1983; 19: 252-8.

10. Scheneider U, Mazur, P. Osmotic consequences of cryoprotectant permeability and its relation to the survival of frozen-thawed embrios. Theriogenology 1984; 21(1):68-73.
11. Johnson AL, Moutray M, Hoffman WE. Effect of ethylene oxide sterilization and storage conditions on canine cortical bone harvested for banking. Vet Surg 1987;16(6):418-22.

12. Johnson AL, Eurell JAC, Schaeffer DJ. Evaluation of canine cortical bone graft remodelling. Vet Surg 1992; 21(4): 293-8.

13. Phillips L, Parker RB, Bloomberg MS. Cortical bone allografts. Comp Cont Educ Pract Vet 1988;10(10):1167-76.

14. Tshamala M, Bree HV, Mattheeuws D. Biomechanical properties of ethilene oxide sterilized and cryopreserved cortical bone allografts. Vet Comp Orthop Traumat 1994; 7(1):25-30.

15. Wagner SD, Manley PA, Radasch RM, Haynes JS. Failure of ethilene oxide-sterilized cortical allografts in two dogs. J Am Anim Hosp Assoc 1994; 30:181-9.

16. Chadieu G, Bardet JF, Morin M. Résultats de l'utilisation dun noveau greffon osseaux (T650) em chirurgie ortopédique et traumatologique vétérinaire. Prat Méd Chir 1992; 27 (3):235-49.

Gioso MA, Benites NR, Kämpf G. Microbiology analysis of dog bones stocked for long period of time on glycerin $98 \%$ at room temperature, aiming allograft bone surgery. Acta Cir Bras [serial online] 2002 Jul-Aug;17(4). Available from URL: http://www.scielo.br/acb.

ABSTRACT - Objective: verify the microorganism growth in bone plus glycerin samples stocked for at least nine years. Methods: microbiology analisys of epiphisis and bone marrow stocked at glycerin 98\% was done. Results: No statistically significant growth was verified. Conclusion: This result means that glycerin is an excellent bone conservation substance for long periods of stockage.

KEY WORDS - Microorganism. Glycerol. Bones. Dog. Fracture. Marrow. Epiphisis.

Conflito de interesse: nenhum Fonte de financiamento: FAPESP

\section{Endereço para correspondência:}

Marco Antonio Gioso

Rua Prof. Dr. Orlando Marques de Paiva, 87

05508-900 São Paulo - SP

Tel.: (11) 3091-1205

Fax: (11) 3091-1211

maggioso@usp.br

Data do recebimento: 16/04/2002

Data da revisão: 03/05/2002

Data da aprovação: 28/05/2002 